\title{
Sex differences in longitudinal pathways from parenting to delinquency
}

\author{
Heleen J. Janssen ${ }^{1}$ • Veroni I. Eichelsheim ${ }^{2}$ • \\ Maja Deković $^{3}$ • Gerben J. N. Bruinsma ${ }^{2}$
}

Published online: 3 August 2017

(C) The Author(s) 2017. This article is an open access publication

\begin{abstract}
In the current study, we examined longitudinally whether boys and girls differed in pathways from parenting to delinquency. Longitudinal mediational models were tested for boys and girls separately in which three parenting dimensions (i.e., monitoring, limit setting, and the quality of the parent-adolescent relationship) were hypothesized to influence adolescents' level of self-control, delinquent attitudes, peer delinquency, and time spent in criminogenic settings, which in turn, were hypothesized to affect delinquency. Using data of 603 adolescents (11-17 years of age at T1) we found mean level differences between boys and girls in parental monitoring, parental limit-setting, self-control, delinquent attitudes, and peer delinquency. The results suggest furthermore that the model linking parenting to delinquency is similar for boys and girls. We found, however, that the indirect effect from the quality of the parent-adolescent relationship through self-control is stronger for girls than for boys.
\end{abstract}

Keywords Adolescent delinquency · Parenting · Gender differences · Self-control · Criminogenic settings $\cdot$ Peer delinquency

Heleen J. Janssen

h.j.janssen@tudelft.nl

Veroni I. Eichelsheim

veichelsheim@nscr.nl

Maja Deković

m.dekovic@uu.nl

Gerben J. N. Bruinsma

gbruinsma@nscr.nl

1 OTB - Research for the Built Environment, Faculty of Architecture and the Built Environment, Delft University of Technology, PO Box 5043, 2600 GA Delft, The Netherlands

2 Netherlands Institute for the Study of Crime and Law Enforcement (NSCR), Amsterdam, The Netherlands

3 Department of Child and Adolescent Studies, Utrecht University, Utrecht, The Netherlands 
Biological sex is one of the strongest and most consistent predictors of delinquent behavior. Although it is well established that males are generally much more involved in delinquent behavior than females, the answer to the question why this so called 'gender gap' exists, is less clear. The generality-specificity debate (Daigle et al. 2007) revolves around whether we need sex-specific theories or whether traditional criminological theories are applicable to both female and male delinquency (Kruttschnitt 2016). Although mainstream criminological theories are put forward as general theories of crime, most of these theories have originally focused on explaining male delinquency (Bartusch and Matsueda 1996). These traditional theories have been criticized for assuming that delinquent behavior of girls can be explained by the same model that explains delinquent behavior of boys.

\section{Explanations for the 'gender gap' in delinquency}

There are three possible explanations for the 'gender gap' in delinquency (Moffitt et al. 2001). The first explanation entails that boys and girls may differ in the risk factors for delinquency. Wong et al. (2010) in their review of 30 European studies found that females had a number of different risk factors for delinquency compared to boys, such as negative life events, physical abuse by parents, and internalizing problems. Overall, however, they found many similarities between males and females in the risk factors for delinquency. In addition, Hubbard and Pratt (2002) found that many of the predictors of female delinquency are similar as those for males, including antisocial attitudes, antisocial peers, and antisocial personalities.

The second explanation entails that the same risk factors play a role in involvement in delinquent behavior for boys and girls, and that boys and girls differ in delinquency involvement because they are differentially exposed to the same risk factors (Moffitt et al. 2001). According to this approach sex differences in delinquency can be explained by differences in the mean levels of risk factors of delinquency (Mears et al. 1998; Moffitt et al. 2001; Worthen 2011).

The third explanation also entails that the same risk factors play a role in involvement in delinquent behavior for boys and girls. It suggests, however, that boys and girls differ in their rates of delinquency because they are differentially affected by the same risk factors. This approach entails that sex differences in delinquency can be explained by differences in the effects of risk factors of delinquency, regardless of possible sex differences in the mean levels of these risk factors (Mears et al. 1998; Moffitt et al. 2001; Worthen 2011).

\section{Sex differences in direct pathways from parenting to delinquency}

When it comes to the 'gender gap' in delinquency, it is often assumed that differences in parenting of boys and girls are an important explanation for differences in engagement in delinquency between boys and girls (Bartusch and Matsueda 1996; Daigle et al. 2007; Fagan et al. 2007; Pauwels and Svensson 2009).

With regard to differences in exposure to parenting practices between boys and girls, explanations for differences in parenting between boys and girls include that, in general, parents may be more concerned with effective socialization of girls because the female role is more dependent on social approval (Tittle et al. 2003), and may be more protective of their daughters than of their sons because they perceive their daughters as being more vulnerable to 
become a victim. Whereas some studies reported few sex differences in mean-levels of parenting practices (see Lytton and Romney 1991), other studies have found that girls are more monitored by their parents compared to boys (Svensson 2003; Worthen 2011). In addition, Higgins (2007) reported that girls received more supervision and discipline than boys.

With regard to the idea that boys and girls differ in how parenting is associated with delinquency, only a few studies found support for some sex-specific associations between parenting and delinquency (Griffin et al. 2000; Worthen 2011). A large number of empirical studies, however, indicated that the associations between parenting and delinquency are similar for boys and girls (see Hoeve et al. 2009). Thus, regarding parenting, sex differences in delinquency are expected to be the result of differences in mean levels of parenting between boys and girls, whereas the effects of parenting on delinquency are expected to be similar between boys and girls.

\section{Sex differences in indirect pathways from parenting to delinquency}

In addition to the observed direct effects of parenting on delinquency, in the recent literature there has been increasing interest in explaining how parenting is indirectly related to delinquency. We derived the most important mechanisms from three major criminological theories (i.e., self-control theory, differential association theory, and routine activity theory) that might explain the relationship between parenting and delinquency. Sex differences in delinquency might be explained by differences in mean levels of the mediators - concepts that were directly derived from these theories (i.e., self-control, delinquent attitudes, delinquent peers, and time spent in criminogenic settings). However, although direct effects of parenting on delinquency are not expected to differ between boys and girls, whether the indirect pathways from parenting to delinquency differ for boys and girls is less clear. In order to examine whether the mechanisms that lead to delinquency for boys and girls are different, we examined whether the indirect pathways from parenting are different for boys and girls. By examining mechanisms derived from major criminological theories simultaneously, we are able to examine whether some mechanisms explain delinquent behavior better for boys or for girls.

Self-control theory (Gottfredson and Hirschi 1990) implicitly assumes that a large part of sex differences in delinquency can be explained by differences in self-control. As stated by Gottfredson and Hirschi (1990), a low level of self-control (i.e., being more impulsive, engaging in risk-taking activities, and preferring immediate gratifications of desires) is the key cause of crime involvement. According to self-control theory (Gottfredson and Hirschi 1990), the mechanisms leading to delinquency are similar for boys and girls. The development of self-control, according to Gottfredson and Hirschi (1990) is a result of parental socialization during early childhood. Parental monitoring, discipline, and support are necessary to foster self-control in children and these differences in self-control are a result of differences in parenting. Differential socialization of boys and girls results in higher levels of self-control in females. Thus, according to self-control theory sex differences in delinquency are a result of mean level differences in self-control.

Gottfredson and Hirschi (1990) stated that self-control is largely determined by parenting practices during early childhood and stable around the ages of 8 to 10. Burt et al. (2006) found, however, that self-control is not as stable after the age of 10 as Gottfredson and Hirschi assumed. They furthermore found substantial effects of parenting on changes in self-control 
after the age of 10 . These results suggest that during adolescence parenting is still related to the development of self-control.

Several empirical studies have examined the role of self-control in explaining the 'gender gap' in delinquency. For example, results of the study of Tittle et al. (2003) indicated that selfcontrol indeed explained the association between sex and crime. The study of Higgins (2007), which included parenting, also found support for the mechanisms proposed by self-control theory. Results indicated that the causal model is similar for boys and girls. That is, ineffective parenting led to low self-control, which explained deviance (including delinquent acts) for both sexes (Higgins 2007). These results indicate that sex differences can be explained by differences in mean levels of self-control, which in turn can be explained by differences in mean levels of parenting between boys and girls.

With regard to differences in effects, Burton et al. (1998) found that self-control was only related to delinquency for boys but not for girls. In contrast, Blackwell and Piquero (2005) found, however, that the effect of parenting on self-control differed between boys and girls. This might indicate that boys and girls are differentially affected by parenting in the development of self-control, meaning that the mechanism leading to the development of self-control is not the same for boys and girls. This is contradictory to what self-control theory assumes (Gottfredson and Hirschi 1990), as no gender specific mechanisms leading to low self-control are specified in this theory.

According to the differential association perspective, delinquent attitudes (i.e., views about whether delinquent acts are acceptable and unacceptable) and peer delinquency are the factors most important for explaining involvement in delinquent behavior. Following this theory, males are more delinquent because they are more exposed to delinquent peers and attitudes in their daily lives compared to females. Similar to self-control theory, differential association theory (Sutherland 1947) assumes that the general process leading to delinquency is invariant across sexes (Warr 2002).

Previous studies have indeed shown that girls are less involved with delinquent peers (Mears et al. 1998; Piquero et al. 2005; Weerman and Hoeve 2012) and have fewer delinquent attitudes (Mears et al. 1998; Heimer and Coster 1999; Piquero et al. 2005). In accordance with differential association theory, studies have shown similar effects of delinquent attitudes on delinquency across sexes (Mears et al. 1998; Piquero et al. 2005). However, although most previous studies indicated that the association between delinquent peers and delinquent behavior are similar for boys and girls (see Hubbard and Pratt 2002; Wong et al. 2010), few studies found sex differences in the effect of peer delinquency on delinquency (Mears et al. 1998; Piquero et al. 2005). Mears et al. (1998) found that boys were more strongly affected by delinquent peers than girls. Similarly, Piquero et al. (2005) found that delinquent peer association predicted delinquency among boys better than among girls.

The differential association perspective also contends that parental monitoring and providing consequences for misbehavior are important indirect causes of delinquency. Individuals who receive less parental monitoring and control are more likely to acquire delinquent attitudes and to engage with delinquent peers, and are therefore more likely to engage in delinquent behavior (Sutherland 1947). Previous research indeed indicated that adolescents who received more effective parenting are less likely to have delinquent attitudes and delinquent peers (Knoester and Haynie 2005; Pardini et al. 2005; Warr 2005). In a study examining the 'gender gap' in violent delinquency, Heimer and Coster (1999) found however, that more indirect parental control, i.e., bond with parents, reduced definitions favorable to violence among girls and not boys. For boys, on the other hand, direct parental control was more important in 
reducing definitions favorable to violence. Their results also showed that violent definitions were similarly related to delinquency across gender.

Although differential association theory assumes that the mechanisms are similar for boys and girls, results from previous studies are mixed. In the present study we focus specifically on the indirect pathways from parenting leading to delinquency through delinquent attitudes and peer delinquency as proposed by the theory and test whether these are similar among girls compared to boys.

In addition to the mechanisms derived from self-control theory and differential association theory, we examined the unique contribution of a relatively new construct to explain the link between parenting and delinquency: time spent in criminogenic settings (Janssen et al. 2016). According to the routine activity perspective (Cohen and Felson 1979) higher levels of involvement in delinquency among boys might be the results of more exposure to criminogenic settings. According to the routine activity perspective, opportunities that arise in routine everyday life are central in explaining criminal behavior. The degree of involvement in delinquency depends on the amount of time that is spent in settings that provide opportunities for delinquent behavior. These criminogenic settings provide temptations, opportunities and lack of control that make delinquent behavior more attractive (Felson and Boba 2010; Wikström et al. 2012). Spending time unsupervised and unstructured socializing with peers in settings with high levels of physical disorder is expected to be particularly conducive for adolescent delinquent behavior (Janssen et al. 2014). The presence of peers makes criminal behavior more rewarding, the absence of adult supervision indicated low social control and unstructured socializing leaves time available for delinquent behavior (Osgood et al. 1996). Higher levels of physical disorder might indicate low social control over the area, which might reduce the perceived risk of getting caught (Sampson and Raudenbush 2004). In addition, the indications that norms and rules are violated might result in more violation of norms and values (Keizer et al. 2008). Although the role of parents is not directly elaborated in the routine activity perspective parents are expected to restrict their children from spending time in criminogenic settings in order to keep them out of trouble (Felson and Boba 2010; Janssen et al. 2014).

Previous studies have found that boys spend more time with peers than girls (Mears et al. 1998; Weerman and Hoeve 2012). Pauwels and Svensson (2009) examined sex differences in the link between parenting and life style risk, which included how often adolescents hang out in the city center, on street corners, and parks. Their results indicated that parental control is similarly related to lifestyle risk between boys and girls.

\section{Present study}

The present study examines how mechanisms derived from mainstream criminological theories about whether parenting is indirectly related to delinquency apply to both boys and girls. Whereas most previous studies examine whether the main effect of sex on delinquency is mediated by parenting, we explicitly examine the magnitude of the direct and indirect effects of parenting on delinquency. The first aim of the present study was to determine whether sex differences exist in the mean level of parenting, self-control, delinquent attitudes, peer delinquency, and time spent in criminogenic settings (i.e., whether boys and girls are differentially exposed to the same risk factors). The second aim was to test whether the integrated model (see Fig. 1) linking parenting indirectly to 
delinquency is similar for boys and girls. We examined to what extent sex differences in these parenting dimensions are related to self-control, delinquent attitudes, peer delinquency, and time spent in criminogenic settings, andin turn the extent to which these mediators are related to delinquency (i.e., whether boys and girls are differentially affected by those risk factors).

The present study contributes to the literature in several ways. First, we examine mechanisms derived from self-control theory, differential association theory and routine activity theory simultaneously to examine sex differences in pathways from parenting to delinquency. Although a fairly large number of studies have already examined the contribution of these mechanisms to explaining the 'gender gap' in delinquency, to our knowledge no study has examined these mechanisms simultaneously. Considering these mechanisms simultaneously could contribute to our understanding of whether and which mechanisms might explain delinquent behavior better for boys or for girls.

Second, in the present study we examined sex differences in mean levels and in effects of multiple parenting dimensions. Both parental control (i.e., parental monitoring and parental limit setting) and parental support (i.e., quality of the parent-adolescent relationship) can be derived from the literature as important for adolescent development (Wright and Cullen 2001; Smetana et al. 2006). Including multiple aspects of parenting might offer insight in whether parental monitoring, parental limit setting, and the quality of the parent-adolescent relationship might be more important for boys or girls.

Third, we used a longitudinal study design in which we examine how parenting is directly and indirectly linked to delinquency two years later.

\section{Method}

\section{Sample}

We used data from the Study of Peers, Activities and Neighborhoods (SPAN), a longitudinal study conducted by the Netherlands Institute for the Study of Crime and Law Enforcement

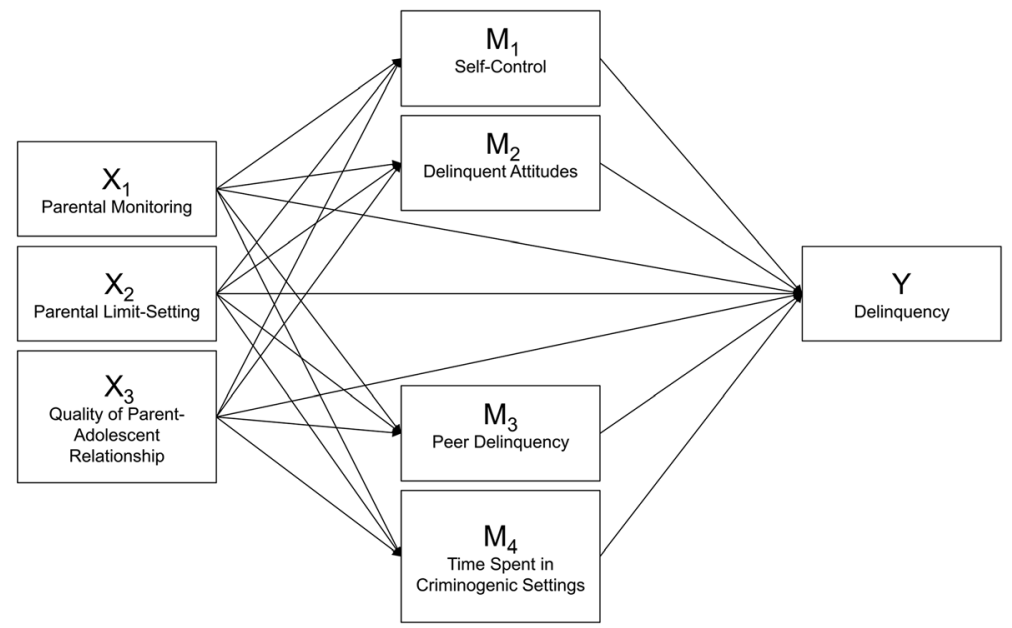

Fig. 1 Mediational Model. 
(NSCR). The SPAN data consist of two waves of data collection among adolescents (1117 years of age at T1) from The Hague and neighboring suburbs in The Netherlands. The first wave of data collection took place in 2008/2009 and the second wave in 2010/2011. Forty schools for secondary education within this area were approached of which ten schools agreed to participate in the study. School response rates did not display any bias with respect to school size or with respect to geographical location, but there was a tendency for certain school types to be somewhat overrepresented. The schools that participated were more often schools with vocational training (lower secondary education) or with pre-university (higher secondary education), and relatively fewer schools with higher general secondary education (middle category). In each school, all first graders and fourth graders were selected, which comprised 943 adolescents. The response rate was $93 \% .^{1}$

The sample used in the present study consisted of 603 adolescents (52\% boys), 11-17 years of age at T1 from The Hague and neighboring suburbs in The Netherlands. No sex differences were found in age distribution $(F=.001, p=.975)$.

Three data sources from the SPAN project were used. A self-report questionnaire was used to measure delinquency, parenting, self-control, delinquent attitudes, and delinquent peers. The questionnaire was individually conducted in groups of four adolescents during a school hour of about 45 min, supervised by a research assistant. In addition, space-time budget interviews combined with systematic social observations were used to measure time spent in criminogenic settings. The space-time budget interview is a structured personal interview, which was conducted individually and face to face with the respondents and was used to measure the social characteristics of time spent in criminogenic settings. The instrument was originally developed by Wikström and Butterworth (2006) in the Peterborough Youth Study and refined in its successor, the Peterborough Adolescent Delinquency Study (PADS+). During the interview, the activities of the adolescent during each hour of four recent days were recorded (always including the previous Friday and Saturday), including the nature of the main activity (e.g., sports, learning), the function of the place (e.g., soccer field, school), persons present in the setting (e.g., teacher, parents), and the geographical location (see also Bernasco et al. 2013).

\section{Delinquency}

The total delinquency frequency was a summary construct based on the scale developed by Wikström and Butterworth (2006) consisting of 20 items asking how often the respondent committed various types of crimes during the past year. The offense types ranged from minor (e.g., vandalism) to serious offenses (e.g., robbery). We used this measure of general delinquency as self-control theory, differential association theory and routine activities theory do not differentiate between different types of delinquency. The following answering categories were used: 0 times; 1 time; 2 times; $3-5$ times; 6-10 times; more than 10 times. Cronbach's alpha was .85 at $\mathrm{T} 2$.

\footnotetext{
${ }^{1}$ Of these 943 adolescents, 27 were not approached because the school was too busy at the moment of data collection; 15 did not participate in the study because parents withdrew them from the study, 13 did not show up at the moment of data collection, six appeared to have moved to another school, and three were ill during the data collection period. From the remaining 878 adolescents, 35 did not complete all research instruments of the study.
} 


\section{Parenting}

Parental monitoring was measured by the use of a summary construct based on the scale developed by Kerr and Stattin (2000); Stattin and Kerr 2000) consisting of five items asking whether the adolescent has to inform his parents about his whereabouts (e.g., "If I go out, my parents want me to tell them where I go, with whom and what I am going to do") using a five-point scale from 0 (totally disagree) to 4 (totally agree). Cronbach's alpha was .77 at T1.

Parental limit setting was a summary construct based on the scale developed by Wikström and Butterworth (2006) consisting of four items that reflect the extent to which parents intervene in rule-breaking behavior (e.g., "If you had been beating up or threatening somebody at school, your parents would tell you off or punish you") using a five-point scale from 0 (totally disagree) to 4 (totally agree). Cronbach's alpha was .62 at T1.

The quality of the parent-adolescent relationship was based on the scale developed by Wikström and Butterworth (2006) and measured by seven items (e.g., "Do you talk to your parents when you have a problem or feel sad about something?") using a four-point scale from 0 (never) to 3 (every day). Cronbach's alpha was .68 at T1.

\section{Mediators}

Self-control was measured by the use of a summary construct based on the scale developed by Grasmick et al. (1993) and consisted of ten items asking about the respondents' general behavior (e.g., "I sometimes find it exciting to do things that may be dangerous") using a five-point scale from 0 (totally agree) to 4 (totally disagree). Cronbach's alpha was .75 at T1.

Delinquent attitudes were operationalized as the adolescent's beliefs about the acceptability of several delinquent acts. The construct was based on a scale that was developed by Loeber, Farrington, Stouthamer-Loeber, and Kammen (1998) and consisted of 16 items asking the respondent about how wrong it would be for someone his age to engage in the behavior (e.g., "Ride a bike through red light") using a four-point scale from 0 (not wrong at all) to 3 (very wrong). The scale is reversed so that a higher score means more delinquent attitudes. Cronbach's alpha was .91 at T1.

Peer delinquency was a summary construct based on the scale developed by Wikström and Butterworth (2006) consisting of six items asking about the amount of delinquent behavior of the adolescent's peers (e.g., "How often do your friends steal something from others or form shops?") using a four-point scale ranging from 0 ((almost) never) to 3 (very often (each week)). Cronbach's alpha was .82 at T1.

Time spent in criminogenic settings was measured as the total number of hours (on the four days covered by the space-time budget interviews) spent unstructured socializing with peers, without adult supervision in settings with high disorder. To assess the level of the physical disorder of the settings were the adolescents spend time, systematic social observation was carried out during the first half of 2012. A grid of 200 by $200 \mathrm{~m}$ that overlaid the maps of The Hague, on which the respondents indicated their locations, was used to select the street segments for the systematic social observation. As trained observers walked the street, they completed an observation checklist, which was based on the instrument used by Raudenbush and Sampson (1999), capturing physical disorder by 13 items (e.g., 'How much trash or broken glass is on the street or sidewalks?'). All items had three answering categories (none, 
one, and more); alpha was $.62 .{ }^{2}$ A setting was indicated as highly disordered as it belonged to the top $25 \%$ of locations with the highest scores on physical disorder (see also Janssen et al. 2014).

For each respondent, we summed the number of hours that met all the following conditions: (1) whether it was spent with at least one peer, (2) in the absence of adults or any other authority figures, (3) included socializing or 'hanging around' as the main activity, and (4) whether it was spent outside a household setting in an area with high physical disorder.

\section{Control variables}

Ethnic background was determined by the birth country of both the parents and the adolescent (following definitions of Statistics Netherlands 2014). If either the adolescent, or the mother or father, was born in Morocco, Turkey, Suriname or the Netherlands Antilles, the adolescent was considered belonging to an ethnic minority. Age at T1 is measured in years.

\section{Analytical approach}

First, we examined to what extent there is a 'gender gap' in delinquency in our data by using ANCOVA. Second, to examine whether boys and girls differ in the exposure to the parenting and mediators, by using MANCOVA for each group of variables, we tested whether there are differences in the levels of parenting (i.e., parental monitoring, parental control, and the quality of the parent-adolescent relationship) and the mediating variables (i.e., self-control, delinquent attitudes, peer delinquency, and time spent in criminogenic settings) including age as covariate.

Third, we inspected intercorrelations to explore whether parenting, mediating variables, and delinquency were differentially correlated between boys and girls. Fourth, to test whether the same model linking parenting to delinquency was applicable to boys and girls, we applied multiple group structural equation modeling in Mplus (Version 7, Muthén and Muthén 19982015). In order to examine whether the paths from parenting to delinquency differed between boys and girls, we compared a constraint model, in which all paths were set equal across the two groups, to an unconstrained model, in which all paths were estimated separately for boys and girls. Differences between the two groups were tested by comparing the Bayesian Information Criterion (BIC) from the constrained and the unconstrained model. Smaller values indicate better fit (Hilbe 2011). Follow-up Wald tests were then conducted in Mplus to identify which paths differed significantly.

Although some scholars claim that the causes of offending are contemporaneous (see for example Agnew 2005), we examined the lagged effect of parenting on delinquency. With this strategy we are able to examine whether parenting is predictive of later behavior. An additional advantage of the lagged effect is that delinquency is measured after the predictor variables.

Because the dependent variable (i.e., total delinquency frequency), was a right skewed count variable, negative binomial models were estimated using maximum likelihood estimation with robust standard errors (Yuan and Bentler 1998; Hox et al. 2010). All indirect effects were estimated in Mplus, which uses the product of coefficients method for testing mediation analyses. The standard errors of the indirect effects were estimated using the multivariate delta method (Bollen 1987).

\footnotetext{
$\overline{{ }^{2} \text { For more details on the reliability }}$ of these SSO data see Hoeben et al. (2016).
} 


\section{Results}

\section{Differences in mean scores}

Table 1 shows the means and standard deviations of delinquency, parenting, and the mediators for boys and girls. As expected, results of the ANCOVA indicated a main effect of sex on delinquency, with boys reporting more involvement in delinquency. Results of the MANCOVA showed a main effect of sex on parenting. The univariate analyses indicated that boys reported less parental monitoring and less parental limit setting compared to girls, whereas boys and girls did not differ in the quality of the parent-adolescent relationship. We also found a main effect of sex on the mediators. Univariate tests revealed that boys have lower levels of self-control, more delinquent attitudes, and more delinquent peers compared to girls. Boys and girls did not differ in the amount of time spent in criminogenic settings. These results indicate that boys are more exposed to most of the risk factors for engagement in delinquent behavior than girls.

\section{Differences in correlations}

Correlations between all assessed variables are shown in the Appendix. Table A1 shows the results for girls and Table A2 for boys. For both boys and girls parental monitoring, parental limit setting, and the quality of the parent-adolescent relationship are negatively related to delinquency. Correlations between parenting and self-control, delinquent attitudes, peer delinquency, and time spent in criminogenic settings were significant and in the expected direction for both boys and girls. However, parenting was more strongly related to peer delinquency and time spent in criminogenic settings among boys $\left(r_{\mathrm{s}}\right.$ range -.217 to -.426$)$ compared to girls $\left(r_{\mathrm{s}}\right.$ range .029 to -.161$)$. Regarding the associations between the mediators and delinquency, all associations, except for time spent in criminogenic settings, were of similar magnitude for both boys and girls. These results indicate that there are more similarities than differences between boys and girls in the relationships between parenting, the mediating variables, and delinquency.

Table 1 Mean scores, standard deviations and MANCOVA results of boys and girls on delinquency, parenting and all mediators

\begin{tabular}{|c|c|c|c|c|c|}
\hline & \multicolumn{2}{|c|}{$\begin{array}{l}\text { Girls } \\
(n=288)\end{array}$} & \multicolumn{2}{|c|}{$\begin{array}{l}\text { Boys } \\
(n=315)\end{array}$} & \multirow[b]{2}{*}{$\mathrm{F}$} \\
\hline & Mean & $\mathrm{SD}$ & Mean & $\mathrm{SD}$ & \\
\hline Delinquency (T2) & 2.60 & 4.11 & 6.53 & 9.51 & $42.53 * * *$ \\
\hline Multivariate test & & & & & $15.34 * * *$ \\
\hline Parental monitoring & 18.34 & 3.70 & 16.27 & 4.15 & $44.16^{* * * *}$ \\
\hline Parental limit setting & 17.06 & 2.55 & 16.27 & 2.75 & $13.86^{* * * *}$ \\
\hline Quality of relationship & 23.16 & 3.47 & 22.83 & 3.21 & 1.55 \\
\hline Multivariate test & & & & & $10.36^{* * *}$ \\
\hline Self-control & 31.07 & 6.13 & 28.42 & 6.22 & $27.63 * * *$ \\
\hline Delinquent attitudes & 31.61 & 8.23 & 34.68 & 9.46 & $20.25 * * *$ \\
\hline Delinquent peers & 8.14 & 2.76 & 9.27 & 3.49 & $23.05 * * *$ \\
\hline Time spent in crim. Settings & 0.59 & 1.60 & 0.87 & 2.14 & 3.41 \\
\hline
\end{tabular}

Note: Age included as covariate 


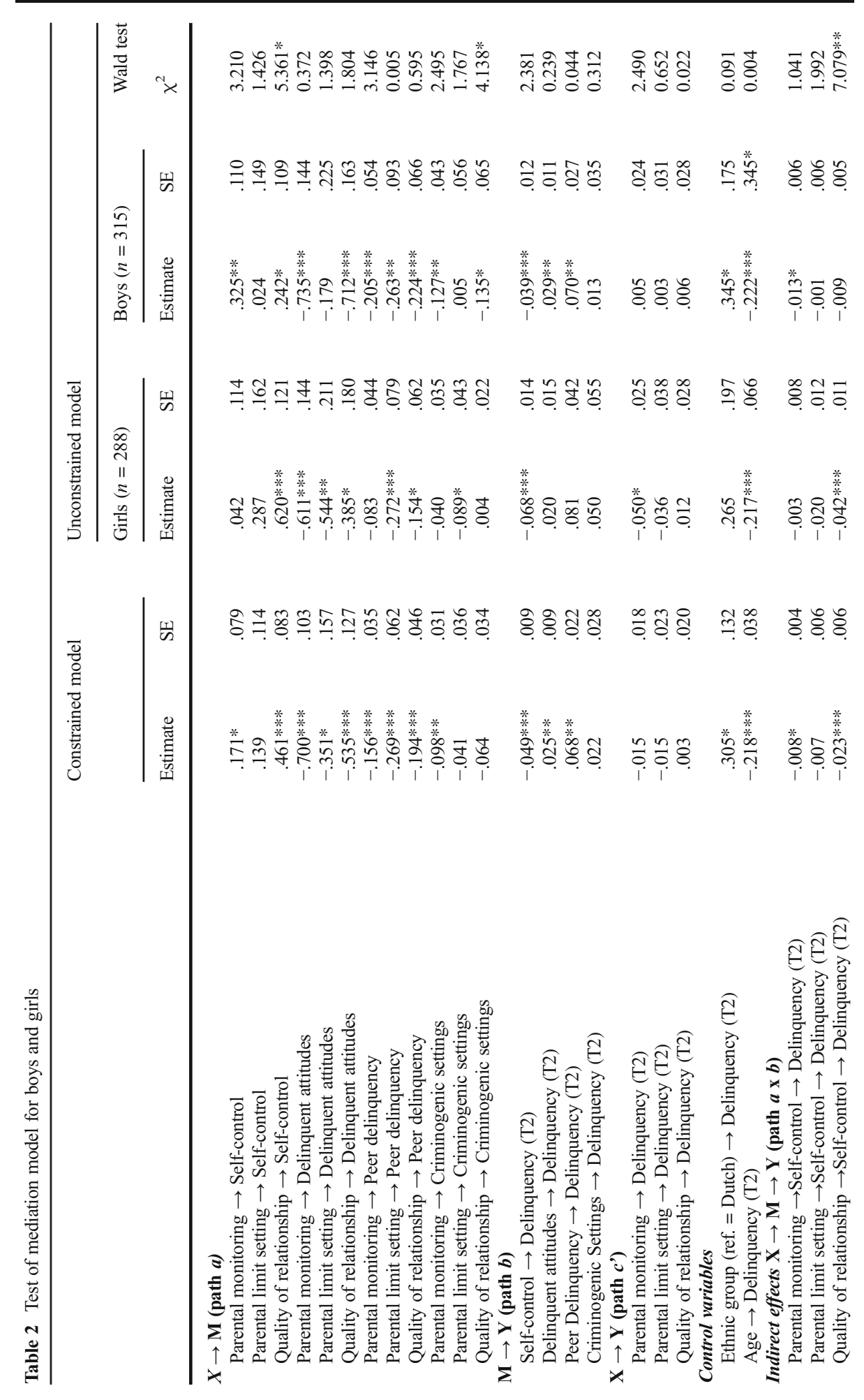




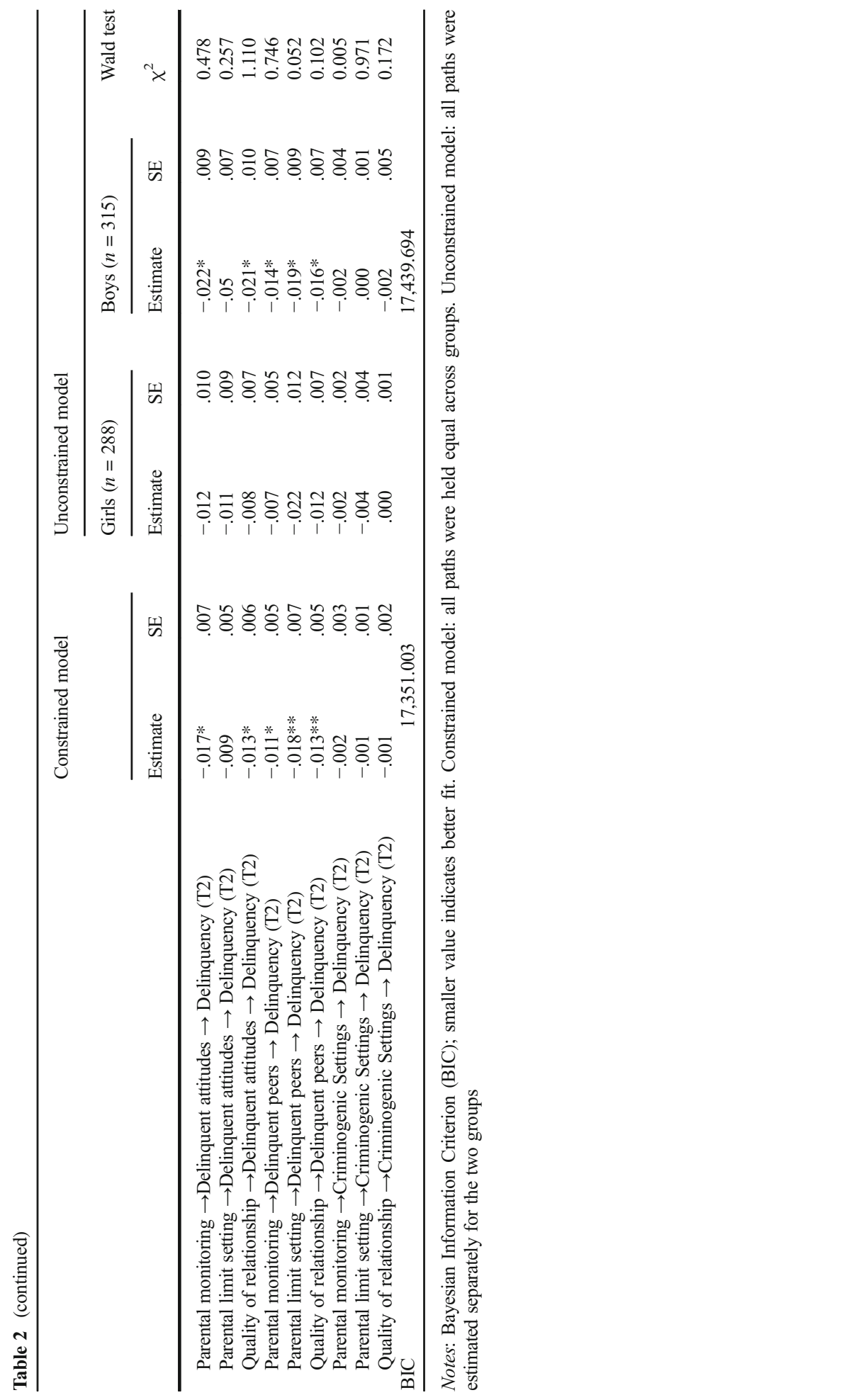




\section{Differences in direct effects from parenting to delinquency}

The results of the constrained and unconstrained models that predicted delinquency at T2 with the three parenting variables at $\mathrm{T} 1$ as predictors indicated that these relationships were similar for boys and girls (Table 2). The Bayesian Information Criteria (BIC) indicated that the constrained model $(B I C=3814.412)$ fit the data better than the unconstrained model $(B I C=3843.993)$. All parenting dimensions were significantly related to delinquency two years later. For both boys and girls, it holds that adolescents who perceive less parental monitoring, less parental limit setting, and a lower quality of the relationship with their parents, are more involved in delinquency two years later.

\section{Differences in indirect effects from parenting to delinquency}

With regard to the indirect pathways from parenting to delinquency, the constrained model indicated that parental monitoring and the quality of the parent-adolescent relationship were indirectly related to delinquency two years later through affecting adolescents' level of selfcontrol, delinquent attitudes, and peer delinquency. Parental limit setting was indirectly related to delinquency trough affecting the adolescents' peer delinquency only. Time spent in criminogenic settings did not mediate any of the relationships between parenting and delinquency controlling for all other indirect pathways.

Parenting was no longer directly related to delinquency two years later, which means that self-control, delinquent attitudes, peer delinquency, and time spent in criminogenic settings together fully mediate the relationships between parenting and delinquency. The level of selfcontrol, delinquent attitudes, and peer delinquency were related to delinquency. Time spent in criminogenic settings, however, was, controlling for all other mediating variables, not related to delinquency two years later.

Although the fit of the constrained model was slightly better than the unconstrained model, Wald tests indicated that the indirect effect of the quality of the parent-adolescent relationship through self-control is stronger for girls than for boys. Whereas the effect from the quality of the parent-adolescent relationship to self-control was stronger for girls than for boys, the effect from self-control to delinquency did not differ between girls and boys. These findings indicate that boys and girls might be differentially affected by the quality of the parent-adolescent relationship.

\section{Discussion and conclusion}

The 'gender gap' in delinquency is well established. Boys are generally much more involved in delinquent behavior compared to girls. In the current study, we examined longitudinally whether boys and girls differed in pathways from parenting to delinquency.

Two possible explanations for the so called 'gender gap' in delinquency were examined. The first explanation entails that boys and girls differ in the extent to which they are exposed to risk factors. Differences in parenting between boys and girls are often assumed to be important explanations for the 'gender gap' in delinquency (Bartusch and Matsueda 1996; Daigle et al. 2007; Fagan et al. 2007; Pauwels and Svensson 2009). The second explanation entails that boys and girls are differentially affected by these risk factors. The aims of the current study were to (I) determine whether sex differences exist in the mean level of parenting, self-control, 
delinquent attitudes, peer delinquency, and time spent in criminogenic settings, and (II) test whether an integrated model linking parenting to delinquency through self-control, delinquent attitudes, peer delinquency, and time spent in criminogenic settings is similar for boys and girls.

In line with previous research, the 'gender gap' in delinquency was also observed in the current study with boys reporting two and a half times more involvement in delinquency than girls. Also consistent with previous work, we found significant sex differences in the mean levels of parenting (Svensson 2003; Worthen 2011). Girls reported significantly higher levels of parental monitoring and parental limit setting. No sex differences, however, were found for the quality of the parent-adolescent relationship. With regard to mediators, girls reported to have higher levels of self-control, less delinquent attitudes, and less delinquent peers, which is also in line with previous empirical studies (Mears et al. 1998; Piquero et al. 2005; Higgins 2007; Weerman and Hoeve 2012). These results offer support for the possible explanation for the sex gap in delinquency that girls are less delinquent because they are less exposed to risk factors for delinquency compared to boys (Moffitt et al. 2001). Differences between boys and girls in the mean levels of these risk factors might be the result of differences in mean levels of parenting. The higher level of parental control girls receive, is related to higher levels of selfcontrol, less delinquent attitudes, and less delinquent peers, which in turn puts them to a lesser extent at risk for involvement in delinquent behavior. Of course, selection effects might play a role here as well. Instead of influencing each other, adolescents might select similar adolescents to socialize with, based on the level of self-control, attitudes or delinquent behavior (Chapple 2005; Knecht et al. 2010).

A second possible explanation for the 'gender gap' in delinquency is that boys and girls are differentially affected by risk factors (Moffitt et al. 2001). Overall, we found that the model linking parenting directly and indirectly to delinquency is remarkably similar for boys and girls. For both boys and girls, effective parenting was related to higher levels of self-control, less delinquent attitudes, less delinquent peers, and less time spent in criminogenic settings. The results also indicated that these risk factors are similarly related to involvement in delinquency two years later across sexes. The results also showed, however, that the quality of the parent-adolescent relationship was stronger related to self-control for girls compared to boys. Higher levels of self-control in girls might be explained by the findings that girls receive higher levels of parental monitoring and parental limit setting, and by the finding that girls benefit more from a relationship of good quality. This means that a good quality relationships with parents characterized by creating an atmosphere of openness in which adolescents feel free to talk to their parents about difficulties and by doing things together, seems to be more important for girls in developing higher levels of self-control than for boys.

It should be noted that time spent in criminogenic settings, derived from routine activity theory (Cohen and Felson 1979), did not mediate the relationships between parenting and delinquency two years later, controlling for the mechanisms derived from self-control theory and differential association theory. Moreover, time spent in criminogenic settings was not related to delinquency, controlled for the other risk factors. These results offer little support for the routine activity perspective. However, results of a previous study have shown that time spent in criminogenic settings was relatively unstable over time (Janssen et al. 2016). The amount of time spent in criminogenic settings at $\mathrm{T} 1$ was not strongly related to the amount spent in criminogenic settings at T2. This might explain why spending time in criminogenic settings was only weakly related to delinquency two years later, but does not necessarily mean that time spent in criminogenic settings is unimportant in explaining delinquent behavior. 
By including measures of parental control as well as a measure of the quality of the parentadolescent relationship, we were able to examine whether certain parenting dimensions might be more or less important for girls than for boys. The results indicated that all parenting dimensions were similarly directly and indirectly related to delinquency for both sexes. However, whereas previous studies on parenting and delinquency usually focused on parental control, the results of the present study indicate that the quality of the parent-adolescent relationship is equally important in explaining adolescent delinquency. This finding is in line with studies in the parenting literature indicating that the quality of the parent-adolescent relationship is important for adolescent development (Deković et al. 2003; Wissink et al. 2006).

As with any study, the results of the present study should be interpreted in the light of some limitations. First, although delinquency is measured at T2, parenting and all mediators were measured at T1, causality cannot be determined. Parenting is a bidirectional and reciprocal process (e.g., Patterson 1995; Pardini et al. 2008; Gault-Sherman 2012). Although adolescents react to the behavior of their parents, parents also respond to the behavior of the adolescent (Gault-Sherman 2012). Regarding the findings of the current study this implies that parenting may affect the adolescent's level of self-control, but also vice versa, i.e., that the level of adolescent self-control may affect the parenting he or she receives. The same applies to the relationships between parenting and the other mediators and to the relationship between parenting and delinquency. It is possible that as adolescents begin to engage with delinquent peers, spend more time in criminogenic settings and in delinquent behavior, this has a negative effect on the relationship with parents with increasing conflicts between parents and the adolescent. Second, we examined how mechanisms derived from mainstream criminological theories differed between boys and girls. The results indicated that the mechanisms included in the present study (i.e., self-control, delinquent attitudes, peer delinquency, and time spent in criminogenic settings) were similar for boys and girls. It is, however, possible that boys and girls differ in risk factors for delinquency that were not included in the present study. For example, previous research has indicated that negative life events, physical abuse by parents, and internalizing problems were risk factors for girls but not for boys (Wong et al. 2010).

Third, all the measures, except for time spent in criminogenic settings, concerned adolescent's perceptions. Although perceptions of adolescents are found to be valid measures of parenting (Abar et al. 2014), self-control (Duckworth and Kern 2011), and delinquency (Thornberry and Krohn 2000), there are certainly disadvantages of using perceptions of adolescents. For example, recent studies have indicated that individuals tend to project their own attitudes and behavior onto their peers and that the effect of peer delinquency is overestimated (Haynie and Osgood 2005; Young and Weerman 2013; Young et al. 2014). To overcome this same-source bias, different sources of information, including peers, parents, teachers, and direct observations should be used (Haynie and Osgood 2005).

Fourth, whereas the space-time budget data were collected during the first wave in $2008 / 2008$, the systematic social observation data were collected in 2012. Within this time period it is possible that certain settings have changed in the level of physical disorder. The time lag between measurement of unstructured and unsupervised socializing, and measurement of disorder adds bias to our measure of time spent in criminogenic settings, which might have resulted in the weak effects of this measure. In addition, the reliability of our measure of disorder and parental limit-setting were low (.62). Although low reliabilities reduce statistical power (Bacon 2004), the intercorrelations are in line with the expected direction. We would like to underline that for future research the scales could be improved. 
The results of the present study indicated that the ways in which parenting is directly and indirectly, through self-control, delinquent attitudes, peer delinquency, related to delinquency are similar across sexes. The current study fits well into the growing body of literature on gender neutrality, examining whether the same theoretical constructs can explain both male and female offending (Brennan et al. 2012; Kruttschnitt 2016). With regard to this generality-specificity debate (Daigle et al. 2007), the results of the present study suggest that mechanisms derived from mainstream criminological theories explain involvement in delinquent behavior for both male and female adolescents. Although girls might benefit more from a warm and supportive relationship with their parents, resulting in higher levels of self-control, parenting is equally important in explaining female delinquency as it is in explaining male delinquency. That is, when adolescents are exposed to ineffective parenting, they are more likely to be involved in delinquency regardless of sex.

The results of the present study might provide directions for possible interventions for the prevention of adolescent delinquent behavior. Intervention strategies aimed at improving parental control as well as the bond between the parent and the adolescent might not only be directly protective for later delinquent behavior, but also indirectly. The results of the present study indicate that these dimensions of parent-adolescent were indirectly related to self-control, delinquent attitudes, and peer delinquency, which in turn were related to delinquency. Furthermore, the results of the present study indicate that there were no sex differences in the assessed direct and indirect pathways from parenting to delinquency, which indicates that boys and girls may equally benefit from interventions aimed at improving parental control and the quality of the parentadolescent relationship.

Acknowledgements This research was supported by the Netherlands Organization for Scientific Research (NWO) under Grant 431-09-021.

We thank Per-Olof Wikström for sharing the questionnaire and the space-time budget interview developed in the Peterborough Adolescent and Young Adult Development Study (PADS+); Beth Hardie, Caroline Moul, and Neema Trivedi for helping train our interview staff; and Kirsten Grandia, Evelien Hoeben, and Lieneke Spel for coordinating the data collection and managing the SPAN fieldwork.

\section{Appendix}

Table A1 Spearman's correlations between all assessed variables for girls $(n=288)$

\begin{tabular}{|c|c|c|c|c|c|c|c|c|}
\hline & 1 & 2 & 3 & 4 & 5 & 6 & 7 & 8 \\
\hline \multicolumn{9}{|l|}{ 1. Parental monitoring } \\
\hline 2. Parental limit setting & $.380 * * *$ & & & & & & & \\
\hline 3. Quality of relationship & $.176^{* *}$ & .110 & & & & & & \\
\hline 4. Self-control & .088 & $.181 * *$ & $.312 * * *$ & & & & & \\
\hline 5. Delinquent attitudes & $-.413 * * *$ & $-.320 * * *$ & $-.305 * * *$ & $-.207 * * *$ & & & & \\
\hline 6. Delinquent peers & $-.271 * * *$ & $-.252 * * *$ & $-.259 * * *$ & $-.323 * * *$ & $.449 * * *$ & & & \\
\hline $\begin{array}{l}\text { 7. Time spent in crim. } \\
\text { Settings }\end{array}$ & $-.132 *$ & $-.161^{* *}$ & .029 & $-.165 * *$ & .094 & $.273 * * *$ & & \\
\hline 8. Delinquency (T2) & $-.190 * * *$ & $-.174 * *$ & $-.141 *$ & $-.373 * * *$ & $.193 * * *$ & $.216^{* * *}$ & $.172 * *$ & \\
\hline 9. Age & $-.218 * * *$ & -.101 & -.047 & -.007 & $.315^{* * *}$ & $.414^{* * *}$ & $.183 * *$ & -.108 \\
\hline
\end{tabular}


Table A2 Spearman's correlations between all assessed variables for boys $(n=315)$

\begin{tabular}{|c|c|c|c|c|c|c|c|c|}
\hline & 1 & 2 & 3 & 4 & 5 & 6 & 7 & 8 \\
\hline \multicolumn{9}{|l|}{ 1. Parental monitoring } \\
\hline 2. Parental limit setting & $.495 * * *$ & & & & & & & \\
\hline 3. Quality of relationship & $.412 * * *$ & $.300 * * *$ & & & & & & \\
\hline 4. Self-control & $.264 * * *$ & $.178 * * *$ & $.235 * * *$ & & & & & \\
\hline 5. Delinquent attitudes & $-.459 * * *$ & $-.334 * * *$ & $-.415^{* * *}$ & $-.305 * * *$ & & & & \\
\hline 6. Delinquent peers & $-.426^{* * *}$ & $-.370 * * *$ & $-.404 * * *$ & $-.402 * * *$ & $.541 * * *$ & & & \\
\hline $\begin{array}{l}\text { 7. Time spent in crim. } \\
\text { Settings }\end{array}$ & $-.301 * * *$ & $-.217 * * *$ & $-.223 * * *$ & $-.210^{* * * *}$ & $.312 * * *$ & $.353 * * *$ & & \\
\hline 8. Delinquency (T2) & $-.204 * * *$ & -.105 & $-.160 * *$ & $-.317 * * *$ & $.252 * * *$ & $.245 * * *$ & .098 & \\
\hline 9. Age & $-.275 * * *$ & $-.253 * * *$ & $-.260 * * *$ & -.033 & $.381 * * *$ & $.488 * * *$ & $.274 * * *$ & -.019 \\
\hline
\end{tabular}

Open Access This article is distributed under the terms of the Creative Commons Attribution 4.0 International License (http://creativecommons.org/licenses/by/4.0/), which permits unrestricted use, distribution, and reproduction in any medium, provided you give appropriate credit to the original author(s) and the source, provide a link to the Creative Commons license, and indicate if changes were made.

\section{References}

Abar, C. C., Jackson, K. M., Colby, S. M., \& Barnett, N. P. (2014). Parent-child discrepancies in reports of parental monitroing and their relationship to adolescent alcohol-related behaviors. Journal of Youth and Adolescence, 44(9), 1688-701.

Agnew, R. (2005). Why do criminal offend? Los Angeles: Roxbury.

Bacon, D. (2004). The contributions of reliability and pretests to effective assessment. Practical Assessment, Research \& Evaluation, 9(3).

Bartusch, D. J., \& Matsueda, R. L. (1996). Gender, reflected appraisals, and labeling: A cross-group test of an interactionist theory of delinquency. Social Forces, 75(1), 145-176.

Bernasco, W., Ruiter, S., Bruinsma, G. J. N., Pauwels, L. J. R., \& Weerman, F. M. (2013). Situational causes of offending: A fixed-effects analysis of space-time budget data. Criminology, 51(4), 895-926.

Blackwell, B. S., \& Piquero, A. R. (2005). On the relationships between gender, power control, self-control, and crime. Journal of Criminal Justice, 33, 1-17.

Bollen, K. A. (1987). Total, direct, and indirect effects in structural equation models. Sociologicl Methodology, 17(1), 37-69.

Brennan, T., Breitenbach, M., Dieterich, W., Salisbury, E. J., \& Van Voorhis, P. (2012). Women's pathways to serious and habitual crime a person-centered analysis incorporating gender responsive factors. Criminal Justice and Behavior, 39(11), 1481-1508.

Burt, C. H., Simons, R. L., \& Simons, L. G. (2006). A longitudinal test of the effects of parenting and the stability of self-control: Negative evidence for the general theory of crime. Criminology, 44(2), 353-396.

Burton, V. S., Cullen, F. T., Evans, T. D., Alarid, L. F., \& Dunaway, R. G. (1998). Gender, self-control, and crime. Journal of Research in Crime and Delinquency, 35(2), 123-147.

Chapple, C. L. (2005). Self-control, peer relations, and delinquency. Justice Quarterly, 22(1), 89-106. doi: $10.1080 / 0741882042000333654$.

Cohen, L. E., \& Felson, M. (1979). Social change and crime rate trends: A routine activity approach. American Sociological Review, 44, 588-608. doi:10.2307/2094589.

Daigle, L. E., Cullen, F. T., \& Wright, J. P. (2007). Gender differences in the predictors of juvenile delinquency: Assessing the generality-specificity debate. Youth Violence and Juvenile Justice, 5(3), 254-286.

Deković, M., Janssens, J. A. M., \& Van As, N. M. C. (2003). Family predictors of antisocial behavior in adolescence. Family Process, 42(2), 223-235.

Duckworth, A. L., \& Kern, M. L. (2011). A meta-analysis of the convergent validity of self-control measures. Journal of Research in Personality, 45, 259-268.

Fagan, A. A., Van Horn, M. L., Hawkins, J. D., \& Arthur, M. W. (2007). Gender similarities and differences in the association between risk ans protective factors and self-reported serious delinquency. Prevention Science, $8,115-124$. 
Felson, M., \& Boba, R. (2010). Crime and everyday life (4th ed.). Thousand Oaks: Sage.

Gault-Sherman, M. (2012). It's a two-way street: The bidirectional relationship between parenting and delinquency. Journal of Youth and Adolescence, 41, 121-145.

Gottfredson, M. R., \& Hirschi, T. (1990). A general theory of crime. Stanford: Stanford University Press.

Grasmick, H. G., Tittle, C. R., Bursik, R. J. J., \& Arneklev, B. J. (1993). Testing the core emperical implications of Gottfredson and Hirschi's general theory of crime. Journal of Research in Crime and Delinquency, 30(5), 5-29.

Griffin, K. W., Botvin, G. J., Scheier, L. M., Diaz, T., \& Miller, N. L. (2000). Parenting practices as predictors of substance use, delinquency, and aggression among urban minority youth: Moderating effects of family structure and gender. Psychology of Addictive Behaviors, 14(2), 174-184.

Haynie, D. L., \& Osgood, D. W. (2005). Reconsidering peers and delinquency: How do peers matter? Social Forces, 84(2), 1109-1130.

Heimer, K., \& Coster, S. D. (1999). The gendering of violent delinquency. Criminology, 37(2), $277-318$.

Higgins, G. E. (2007). Gender and self-control theory: Are there differences in the measures and the Theory's causal model? Criminal Justice Studies: A Critical Journal of Crime, Law and Society, 17(1), 33-55.

Hilbe, J. M. (2011). Negative binomial regression (Second ed.). Cambridge: Cambridge University Press.

Hoeben, E., Steenbeek, W., \& Pauwels, L. (2016). Measuring disorder: observer bias in systematic social observations at streets and neighborhoods. Journal of Quantitative Criminology, 1-29.

Hoeve, M., Dubas, J. S., Eichelsheim, V. I., Van Der Laan, P. H., Smeenk, W., \& Gerris, J. R. M. (2009). The relationship between parenting and delinquency: A meta-analysis. Journal of Abnormal Child Psychology, 37, 749-775.

Hox, J. H., Maas, C. J. M., \& Brinkhuis, M. J. S. (2010). The effect of estimation method and sample size in multilevel structural equation modeling. Statistica Neerlandica, 64(2), 157-170.

Hubbard, D. J., \& Pratt, T. C. (2002). A meta-analysis of the predictors of delinquency among girls. Journal of Offender Rehabilitation, 34(3), 1-13.

Janssen, H. J., Deković, M., \& Bruinsma, G. J. N. (2014). Parenting and time adolescents spend in criminogenic settings: A between- and within-person analysis. British Journal of Criminology, 54, 551-567. doi:10.1093 /bjc/azu032.

Janssen, H. J., Eichelsheim, V. I., Deković, M., \& Bruinsma, G. J. N. (2016). How is parenting related to adolescent delinquency? A between- and within-person analysis of the mediating role of self-control, delinquent attitudes, having delinquent friends, and time spent in criminogenic settings. European Journal of Criminology, 13(2), 169-194.

Keizer, K., Lindenberg, S., \& Steg, L. (2008). The spreading of disorder. Science, 322(5908), 1681-1685.

Kerr, M., \& Stattin, H. (2000). What parents know, how they know it, and several forms of adolescent adjustment: Further support for a reinterpretation of monitoring. Developmental Psychology, 36, 366-380.

Knecht, A., Snijders, T. A. B., Baerveldt, C., Steglich, C. E. G., \& Raub, W. (2010). Friendship and delinquency: Selection and influence processes in early adolescence. Social Development, 19(3), 494-514. doi:10.1111 j.1467-9507.2009.00564.x.

Knoester, C., \& Haynie, D. L. (2005). Community context, social integration into family, and youth violence. Journal of Marriage and Family, 67, 767-780.

Kruttschnitt, C. (2016). The politics, and place, of gender in research on crime. Criminology, 54(1), 8-29. doi:10.1111/1745-9125.12096.

Loeber, R., Farrington, D. P., Stouthamer-Loeber, M., \& Kammen, W. B. v. (1998). Antisocial behavior and mental health problems: Explanatory factors in childhood and adolescence. Mahwah: Lawrence Erlbaum.

Lytton, H., \& Romney, D. M. (1991). Parents' differential socialization of boys and girls: A meta-analysis. Psychological Bulletin, 109(2), 267-296.

Mears, D. P., Ploeger, M., \& Warr, M. (1998). Explaining the gender gap in delinquency: Peer influence and moral evaluations of behavior. Journal of Research in Crime and Delinquency, 35(3), 251-266.

Moffitt, T. E., Caspi, A., Rutter, M., \& Silva, P. A. (2001). Sex differences in antisocial behaviour: Conduct Disorde, delinquency, and violence in the Dunedin longitudinal study. Cambridge: Cambridge University Press.

Muthén, L.K., \& Muthén, B.O. (1998)-2015. Mplus user's guide. Los Angeles: Muthén \& Muthén.

Osgood, D. W., Wilson, J. K., O'Mally, P. M., Bachman, J. G., \& Johnston, L. D. (1996). Routine activities and individual deviant behavior. American Sociological Review, 61, 635-655.

Pardini, D. A., Loeber, R., \& Stouthamer-Loeber, M. (2005). Developmental shifts in parent and peer influences on boys' beliefs about delinquent behavior. Journal of Research on Adolescence, 15(3), 299-323.

Pardini, D. A., Fite, P. J., \& Burke, J. D. (2008). Bidirectional associations between parenting practices and conduct problems in boys from childhood to adolescence: The moderating effect of age and AfricanAmerican ethnicity. Journal of Abnormal Child Psychology, 36(5), 647-662. 
Patterson, G. R. (1995). Coercion as a basis for early age of onset for arrest. Coercion and punishment in longterm perspectives, 81-105. Cambridge: Cambridge University Press.

Pauwels, L., \& Svensson, R. (2009). Adolescent lifestyle risk by gender and ethnic background: Findings from two urban samples. European Journal of Criminology, 6, 5-23.

Piquero, N. L., Gover, A. R., MacDonald, J. M., \& Piquero, A. R. (2005). The influence of delinquent peers on delinquency: Does gender matter?. Thousand Oaks: Sage.

Raudenbush, S. W., \& Sampson, R. J. (1999). Ecometrics: Toward a science of assessing ecological settings, with application to the systematic social observation of neighborhoods. Sociological Methodology, 29, 1-41.

Sampson, R. J., \& Raudenbush, S. W. (2004). Seeing disorder: Neighborhood stigma and the social construction of "broken windows". Social Psychology Quarterly, 67(4), 319-342.

Smetana, J. G., Campione-Barr, N., \& Metzger, A. (2006). Adolescent development in interpersonal and societal contexts. Annual Review of Psychology, 57, 255-284.

Statistics Netherlands (2014). Definitions: Origin. Retrieved from http://www.cbs.nl/en$\mathrm{GB} / \mathrm{menu} / \mathrm{methoden} /$ begrippen/default.htm?ConceptID=315.

Stattin, H., \& Kerr, M. (2000). Parental monitoring: A reinterpretation. Child Development, 71(4), 1072-1085.

Sutherland, E. H. (1947). Principles of criminology. Philadelphia: Lippincott.

Svensson, R. (2003). Gender differences in adolescent drug use: The impact of parental monitoring and peer deviance. Youth \& Society, 34(3), 300-329.

Thornberry, T. P., \& Krohn, M. D. (2000). The self-report method for measuring delinquency and crime. Criminal Justice, 4(1), 33-83.

Tittle, C. R., Ward, D. A., \& Grasmick, H. G. (2003). Gender, age, and crime/deviance: A challenge to selfcontrol theory. Journal of Research in Crime and Delinquency, 40(4), 426-453.

Warr, M. (2002). Companions in crime: The social aspects of criminal conduct. Cambridge: Cambridge University Press.

Warr, M. (2005). Making delinquent friens: Adult supervision and children's affiliations. Criminology, 43, 77106.

Weerman, F. M., \& Hoeve, M. (2012). Peers and delinquency among girls and boys: Are sex differences in delinquency explained by peer factors? European Journal of Criminology, 9(3), 228-244.

Wikström, P.-O. H., \& Butterworth, D. A. (2006). Adolescent crime: Individual differences \& lifestyles. Cullompton: Willan.

Wikström, P.-O. H., Oberwittler, D., Treiber, K., \& Hardie, B. (2012). Breaking rules: The social and situational dynamics of young people's urban crime. Oxford: Oxford University Press.

Wissink, I. B., Deković, M., \& Meijer, A. M. (2006). Parenting behavior, quality of the parent-adolescent relationship, and adolescent functioning in four ethnic groups. The Journal of Early Adolescence, 26, 133159.

Wong, T. M. L., Slotboom, A.-M., \& Bijleveld, C. C. J. H. (2010). Risk factors for delinquency in adolescent and young adult females: A European review. European Journal of Criminology, 7(4), 266-284.

Worthen, M. G. F. (2011). Gender differences in parent-child bonding: Implications for understanding the gender gap in delinquency. Journal of Crime and Justice, 34(1), 3-23.

Wright, J. P., \& Cullen, F. T. (2001). Parental efficacy and delinquent behavior: Do control and support matter? Criminology, 39(3), 677-706.

Young, J. T. N., \& Weerman, F. M. (2013). Delinquency as a consequence of misperception: Overestimation of friends' delinquent behavior and mechanisms of social influence. Social Problems, 60(3), 334-356.

Young, J. T. N., Rebellion, C. J., Barnes, J. C., \& Weerman, F. M. (2014). Unpacking the black box of peer similarity in deviance: Understanding the mechanisms linking personal behavior, peer behavior, and perceptions. Criminology, 52(1), 60-86.

Yuan, K.H., \& Bentler, P.M. (1998). Robust mean and covariance structure analysis. British Journal of Mathematical and Statistical Psychology, 51(1), 63-88. 